\title{
How are biodiversity and dispersal of species affected by the management of roadsides? A systematic map protocol
}

\author{
Claes Bernes ${ }^{1 *}$, James M. Bullock² Simon Jakobsson ${ }^{3}$, Maj Rundlöf ${ }^{4}$, Kris Verheyen ${ }^{5}$ and Regina Lindborg ${ }^{3}$
}

\begin{abstract}
Background: In many parts of the world, roadsides are regularly managed for traffic-safety reasons. Hence, there are similarities between roadsides and certain other managed habitats, such as wooded pastures and mown or grazed grasslands. In contrast to roadsides, the latter habitats have declined rapidly in Europe during the last century, and today only a fraction of their former extent remains. For many species historically associated with these habitats, roadsides may therefore function as new primary habitats or as dispersal corridors in fragmented landscapes. Current recommendations for roadside management to promote conservation values are largely based on studies of plants in semi-natural grasslands, although such areas often differ from roadsides in terms of environmental factors and impacts. Moreover, roadsides provide habitats not only for plants but also for many insects, especially if they are sandy and exposed to the sun. For these reasons, stakeholders in Sweden have emphasised the need for more targeted management recommendations, based on actual studies of roadside biodiversity.

Methods: The proposed systematic map is intended to provide an overview of the available evidence on how biodiversity is affected by various forms of roadside management, and how such management influences the dispersal of species along roads or roadsides. Relevant interventions include e.g. mowing, shrub removal, control of invasive/ nuisance species, sowing or planting, burning, grazing by livestock, scraping and ditching. Non-intervention or alternative forms of roadside management will be used as comparators. Relevant outcomes include measures of species or genetic diversity, the abundance of individual species or groups of organisms, species distribution patterns, and movement rates of individuals or propagules. Searches will be made for peer-reviewed and grey literature in English and several other languages. No geographical restrictions will be applied, and all species and species groups will be considered.
\end{abstract}

Keywords: Road ecology, Roadside management, Biodiversity, Species dispersal, Semi-natural grasslands, Linear landscape elements, Refugia

\section{Background}

\section{Roadsides as habitats and dispersal corridors}

The creation of road networks has been a critical component of the development of our civilisation. During millennia, these networks have evolved from foot trails to complex highway systems. The modern transportation

\footnotetext{
*Correspondence: claes.bernes@eviem.se

${ }^{1}$ Mistra Council for Evidence-Based Environmental Management, Stockholm Environment Institute, Box 24218, SE-104 51 Stockholm, Sweden

Full list of author information is available at the end of the article
}

infrastructure has major impacts on the surrounding landscape, which traditionally have been studied mainly within the field of geography (cf. [1]).

In the 1970s, coincident with the development of landscape ecology, conservation biologists became interested in how roads fragment the landscape and interact with landscape processes [2]. Establishing a new road segment or road network in a landscape has been described as being equivalent to adding a new ecosystem to the existing one [1]. However, the concept of 'road ecology', a specific sub-discipline of ecology, was not coined until 1998 by landscape ecologist Richard T.T. Forman [3]. 
Although a relatively new area of research, road ecology has been the subject of a fairly large number of studies. The growing scientific interest in road ecology is also reflected in international conferences arranged by ICOET in North America (www.icoet.net), IENE in Europe (www.iene.info), ANET in Asia/Australia (www. ecoltrans.net) and the global ICCB (www.iccb-eccb2015. org).

The vast majority of studies on ecological effects of roads have focused on direct negative impacts on abiotic aspects like hydrology, sediment and debris transport, water and air chemistry, microclimate and levels of noise, wind and light adjacent to roads [4]. Negative biotic effects such as wildlife collisions, population fragmentation, road avoidance behaviour and dispersal of invasive species have also been acknowledged [3].

During the last decades, roadsides have been highlighted as important dispersal corridors in many subdisciplines of biology. Plants and animals that use roads as dispersal corridors are often generalist species [4], and invasive species, predominantly generalists, may hence be dispersed more easily along roadsides than native ones. In fragmented landscapes, however, roadsides can also favour native species, e.g. spiders [5], insects [6, 7], and plants [8].

Plant dispersal in rural areas is usually mediated by seeds, but grazing animals have become less important as dispersal vectors, partly being replaced in that role by motor vehicles and agricultural machinery $[9,10]$. No plant species have evolved specifically to be dispersed via motor vehicles, but Zwaenepoel et al. [11] found that species dispersed in this way had significantly more persistent seed banks than other species, indicating that vehicles can aid the dispersal through space of seeds that traditionally were dispersed through time.

Recently, roadsides have been discussed as specific habitats in their own right rather than merely as small dispersal refugias or stepping-stone habitats [12-14]. For instance, in the Netherlands and Australia, where large parts of the rural landscape have been transformed to intensively used farmland, roadsides are important habitats for native vegetation $[15,16]$.

Roadsides provide habitats not only for plants, but also for insects and small mammals [17]. Mammals often use roadsides when they move around in the landscape $[18,19]$. Flower-rich road verges attract bumblebees and other wild bee species, hoverflies, butterflies and many other insects that depend on nectar and/or pollen [7]. Moreover, roadsides can serve as reproductive habitats for many insects, especially if they are sandy and exposed to the sun. Such areas may also attract animals that formerly resided mainly on seashores, sandy banks, sand dunes, fallows, dry meadows, alvar habitats etc. Sandy and warm environments are important not least for snakes and lizards, some of which are now found almost exclusively along roads and in other places where sand has been exposed due to human disturbance [20].

For several red-listed species, roadsides are the most important habitats, or among the most important ones [20]. For example, one of the most threatened butterflies in Sweden, the Reverdin's blue (Plebejus argyrognomon) occurs only along sunny roadsides where its larval plant grows (wild liquorice, Astragalus glycyphyllos).

\section{Roadside management}

The occurrence of animals and plants along roads is highly dependent on how the roadsides are managed [4]. In many parts of the world, roadsides are regularly mowed for traffic-safety reasons, and their vegetation will then remain at the same successional stage year after year. Hence, there are similarities in management and abiotic conditions between roadsides and habitats such as wooded pastures and mown or grazed semi-natural grasslands [21]. In contrast to roadsides, the latter habitats have declined rapidly in Europe during the last century [22], and today only a fraction of their former extent remains.

Differences in mowing regimes may affect both animal and plant populations. Mowing of roadsides late in the season is considered to be important for favouring flowering and seed production. It also favours disturbance-tolerant species, while species representing early-successional stages will eventually disappear. On the other hand, early mowing can lead to re-flowering in the later parts of the season [23], which otherwise may be characterised by a lack of nectar and pollen resources [24]. Cut vegetation, or litter, should ideally be removed from nutrient-rich roadsides to promote plant species that are adapted to low nutrient levels [25].

In some cases, roadside management includes more powerful ways of removing vegetation and reversing late-successional vegetation stages, such as burning, harrowing or scraping. In contrast, roadsides on dry and nutrient-poor soils may require very little management.

In Sweden, roadside management is currently being discussed as an important part of overall landscape management for biodiversity. The Swedish Board of Agriculture recently estimated that 190,000 ha of managed grasslands occur along infrastructure in Sweden, 164,000 ha of which constitute roadsides [26]. This is close to the total amount of semi-natural grasslands in Sweden (ca. 250,000 ha). Many species that historically mainly were associated with meadows and pastures now thrive along roads. For example, almost 300 animal and plant species included in the Swedish Red List of threatened species are found in roadside habitats [27]. 
More recently, there has been a growing interest in other roadside functions, especially biomass production (e.g. [28]). Feedstocks for bioenergy production are heavily searched for, and roadsides could provide a considerable extra source given their large extent. Furthermore, biomass production on roadsides could reduce management costs. Such multifunctional roadside use, with a potential to create win-wins for biodiversity conservation and bioeconomy, could be considered when designing future roadside management plans.

Current recommendations for roadside management to promote conservation values are largely based on botanical research studies of open semi-natural grasslands such as meadows and pastures [29]. However, the use of road salt for de-icing, ditching and reinforcement activities, sowing of exotic plant material and other measures specific to infrastructure maintenance are likely to impact species and communities differently than traditional management of open grasslands. Moreover, much of the existing evidence on ecological effects of roadside management is comprised of grey literature not assessed by external reviewers. For these reasons, key stakeholders in Sweden have emphasised the need for more targeted management recommendations, based on actual studies of roadsides.

\section{Topic identification, scientific basis and stakeholder input}

The topic of the proposed systematic map was suggested by the Swedish Board of Agriculture at a meeting with stakeholders arranged by the Mistra Council for Evidence-Based Environmental Management (EviEM) in 2013.

A pilot review of the present state of knowledge on biodiversity aspects of roadside management was then conducted by the EviEM Secretariat. The review was largely based on contacts with specialists and other stakeholders, including representatives of the Swedish Transport Administration, the Swedish Environmental Protection Agency, the Swedish Board of Agriculture, the Swedish Species Information Centre, the Swedish University of Agricultural Sciences, Lund and Uppsala universities, the Swedish Butterfly Monitoring Scheme, the Triekol research programme, the Lill-NILS grassland monitoring programme and the environmental consultancy firm Calluna. The pilot review also included a brief scoping study of relevant scientific literature.

The Triekol programme recently published a narrative review of about 400 scientific articles with possible relevance to the effects of roadside management on vascular plants, but nearly all of these articles were based on studies of meadows and other semi-natural grasslands rather than actual roadsides [30]. It was concluded that systematic investigations of the management of roadside vegetation are almost completely absent (see also [29]).

A few recent reviews have focused on linear elements in the landscape, including roadsides. An Australian systematic review by Doerr et al. [31] studied to what extent plants and animals use linear structures as corridors for dispersal, but only four Australian studies of roadsides were included. The review produced a number of management recommendations relevant to Australia, but it also identified significant knowledge gaps, and it is currently being updated [32]. Ansong and Pickering [10] systematically reviewed the literature on seed dispersal by cars, and several other review articles on this topic have recently been published (e.g. [9, 33]). Suárez-Esteban et al. [34] have reviewed studies that compare vegetation along road verges and other linear gaps in the landscape with that of adjacent habitats.

Much of the useful evidence on the topic of our review is likely to be published in grey literature. For instance, there is probably a large volume of grey literature on insects and roadside management in e.g. Switzerland, the Netherlands, Germany, and the United Kingdom (Lars Pettersson, pers. comm.). There was consensus among contacted stakeholders that roadside habitats in Sweden have great conservation value for native animals and plants. Government agencies and researchers agreed that there is a need for a systematic review of the effects of different management techniques. In particular, they underlined the importance of analysing the impacts of roadside management on (i) insects, (ii) dispersal or movement rates of species along roadsides, (iii) alien versus native animal and plant species.

It was pointed out that several questions relating to roadside management remain unanswered. Do animals benefit from management regimes targeted towards promoting floristic values? Are roadsides 'ecological traps' that attract large number of insects but cause low reproductive rates and high mortality? Should management activities be differentiated depending on road size, landscape context (forested or agricultural landscapes), landuse history etc.? Finally, many stakeholders emphasised that effects of roadside management on the establishment and dispersal of alien species need to be evaluated.

Prior to completion of the draft review protocol, EviEM arranged a meeting with Swedish stakeholders with a specific interest in road management. The meeting was attended by representatives of government agencies, municipalities, universities, research institutes, and environmental organisations and consultants.

Among other things, the stakeholders discussed the physical and geographical scope of the proposed review. In this context, it was suggested that a roadside be defined 
as the unpaved zone adjacent to a road that is exposed to roadside management. On small, unpaved roads, studies of the road itself could also be included in the review. Moreover, it is vital to consider the interaction between the roadside and the surrounding landscape. The stakeholders also pointed out that the feasibility of transferring foreign experience of roadside management to Swedish conditions is dependent on e.g. soil types, management methods and biodiversity aspects. For instance, studies of ruderal roadside habitats are easier to generalise than studies of mown grassland. Nevertheless, the stakeholders found it reasonable that the review include relevant studies from any part of the world's temperate, boreal and subalpine zones, and also areas in the subtropical or tropical zones that have a cool climate due to high altitude.

\section{Objectives}

The proposed systematic map is intended to provide an overview of the available evidence on how biodiversity is affected by various forms of roadside management, and how such management influences the dispersal of species along roads or roadsides.

Other infrastructural habitats such as railways, powerline corridors, buffer strips etc. will not be included in the map, since their qualities and management differ radically from those of roadsides. Nor will studies of semi-natural meadows or pastures be include-these habitats have been extensively covered by other reviews, and they are not subject to the same set of environmental impacts as roadsides.

Guided by the findings of the systematic map, we also intend to identify subtopics that may be suitable for full systematic review.

\section{Primary question}

How are biodiversity and dispersal of species affected by the management of roadsides?

\section{Components of the primary question}

Population Roadside habitats and the species found within them.

Intervention Roadside management, e.g. mowing, removal of shrubs and saplings, pruning, coppicing, control of invasive/nuisance species, herbicide use, sowing or planting, burning, grazing by livestock, harrowing, scraping, macadamisation, ditching and maintenance of ditches.

Comparator Non-intervention or alternative forms of roadside management.
Outcomes

(i) Measures of local or regional diversity of animals, plants or fungi, e.g. alpha/beta/gamma species diversity, genetic diversity, abundance of individual species (including rare/ protected species), or abundance of functional/taxonomic groups of organisms.

(ii) Measures of species dispersal along roads or roadsides, e.g. species distribution patterns or movement rates of individuals or propagules.

\section{Methods}

\section{Search terms}

The review team has conducted a scoping exercise to assess alternative search strings, testing them against a set of some 20 articles known to be relevant. The exercise resulted in the selection of the following search terms:

Population roadside*, "road side", (road* AND (verge* OR edge $\left.{ }^{*}\right)$ ), roundabout", "traffic island", "median strip", "central reservation", boulevard*, parkway*, (avenue $^{*}$ AND tree ${ }^{*}$ )

Outcomes *diversity, dispers", species, abundance, vegetation

The terms within the 'population' and 'outcomes' categories will be combined using the Boolean operator 'OR'. The two categories will then be combined using the Boolean operator 'AND'. An asterisk (*) is a 'wildcard' that represents any group of characters, including no character.

No time, language or document type restrictions will be applied.

At some of the websites mentioned below, searches will also be made for Danish, Dutch, French, German, Norwegian, Spanish or Swedish counterparts to the above terms. Both English and non-English search terms may have to be customised to individual websites, since many of these do not accept long and complex search strings. Final search strings used for each search will be recorded in an appendix to the review, together with search dates.

\section{Publication databases}

The search aims to include the following online databases:

1. Academic Search Premier.

2. Agricola. 
3. Biological Abstracts.

4. GeoBase + GeoRef.

5. Helda (University of Helsinki).

6. IngentaConnect.

7. JSTOR.

8. Libris.

9. Scopus.

10. SwePub.

11. Transport Research International Documentation (TRID).

12. Web of Science.

13. Wiley Online Library.

\section{Search engines}

Internet searches will be performed using the following search engines:

Google (www.google.com). Google Scholar (scholar.google.com).

In each case, the first 200 hits (based on relevance) will be examined for appropriate data.

\section{Specialist websites}

Websites of the specialist organisations listed below will be searched for links or references to relevant publications and data, including grey literature.

Australasian Network for Ecology and Transportation (www.ecoltrans.net).

Collaboration for Environmental Evidence

(www.environmentalevidence.org).

Conservation Evidence (www.conservationevidence.com).

Environment Canada (www.ec.gc.ca).

European chapter of the Society for Ecological

Restoration (SER) (chapter.ser.org/europe/).

European Commission Joint Research Centre (ec.europa.eu/jrc/).

European Environment Agency (www.eea.europa.eu). Highways England (www.gov.uk/government/ organisations/highways-england).

Infra Eco Network Europe (www.iene.info). International Conferences on Ecology and Transportation (www.icoet.net).

International Union for Conservation of Nature

(www.iucn.org).

Natural England (publications.naturalengland.org.uk).

Natural Resources Canada (www.nrcan.gc.ca).

Nordic Council of Ministers (www.norden.org).

Norwegian Environment Agency

(www.miljodirektoratet.no).

Norwegian Institute for Nature Research

(www.nina.no).

\author{
Swedish County Administrative Boards \\ (www.lansstyrelsen.se). \\ Swedish Environmental Protection Agency \\ (www.naturvardsverket.se). \\ Swedish Transport Administration (www.trafikverket.se). \\ Swedish University of Agricultural Sciences \\ (www.slu.se). \\ UK Centre for Ecology and Hydrology \\ (www.ceh.ac.uk). \\ UK Environment Agency \\ (www.environment-agency.gov.uk). \\ United Nations Environment Programme (www.unep.org). \\ US Department of Transportation \\ (www.transportation.gov). \\ United States Environmental Protection Agency \\ (www.epa.gov).
}

\section{Other literature searches}

As a check of the comprehensiveness of our searches, relevant articles and reports will also be searched for in bibliographies of literature reviews. Moreover, each member of the review team will use national and international contacts to get information on current research related to the topic of the review, and also to find nonpeer-reviewed literature, including reports published in e.g. Danish, Dutch, French, German, Norwegian, Spanish and Swedish. In addition, unpublished data may be available from consultants or local authorities involved in roadside management. Stakeholders will be asked to suggest suitable contacts.

\section{Screening of articles}

When screening a sample of 100 articles found in Web of Science with the search string above, we noted that only about a third of the articles could safely be excluded as irrelevant based on their titles alone. For that reason, articles found by searches in databases will first be evaluated for inclusion based on titles and abstracts combined. This assessment will be made by a single reviewer, who in cases of uncertainty will tend towards inclusion. A subset consisting of at least 100 of the articles will be assessed by at least two reviewers. A kappa statistic relating to the assessments will be calculated. If this statistic indicates that the reviewers are inconsistent in their assessment $(\kappa<0.6)$, discrepancies will be discussed and the inclusion criteria will be clarified or modified.

Next, each article found to be potentially relevant on the basis of title and abstract will be judged for inclusion by a reviewer studying the full text. Again, the reviewer will tend towards inclusion in cases of uncertainty. Final decisions on whether to include doubtful cases will be taken by the review team as a whole. 
Studies or datasets found by other means than database searches will be entered at the second stage of this screening process.

A list of studies rejected on the basis of full-text assessment will be provided in an appendix together with the reasons for exclusion.

\section{Study inclusion criteria}

Each study must pass each of the following criteria in order to be included.

- Relevant subjects Roadside habitats and the species found within them. A roadside is defined as the unpaved zone a road that is exposed to roadside management. On small, unpaved roads, studies of the road itself may also be included.

While stakeholders suggested that the review include studies of roadside management in temperate, boreal and subalpine zones (and high-altitude areas in subtropical and tropical zones), we found little reason to impose any geographical restriction at all, since many basic ecological mechanisms will be the same everywhere. Therefore, we will include relevant studies from anywhere in the world.

- Relevant types of intervention Roadside management, including but not restricted to mowing, removal of shrubs and saplings, pruning, coppicing, control of invasive/nuisance species, herbicide use, sowing or planting, burning, grazing by livestock, harrowing, scraping, macadamisation, ditching and maintenance of ditches. Such measures will also be considered as relevant where they have been applied during construction of new roadsides.

- Relevant type of comparator Non-intervention or alternative forms of roadside management.

Comparisons can in principle be made both temporally and spatially. Studies with a 'BA' (Before/After) design compare data collected at the same site prior to and following an intervention. Other studies may be based on comparison of different parts of a roadside, some that have been subject to a certain kind of management and some that have not. These may be termed as ' $\mathrm{Cl}$ ' (Comparator/Intervention) studies, or 'BACI' (Before/After/Comparator/Intervention) if they present data collected both before and after the intervention.

- Relevant types of outcome:

(i) Measures of local or regional biodiversity, e.g. alpha/beta/gamma species diversity, genetic diversity, abundance of individual species (including rare/protected species) or abundance of functional/taxonomic groups of organisms.

(ii) Measures of species dispersal along roads or roadsides, e.g. species distribution patterns or movement rates of individuals or propagules.

All species of animals, plants and fungi will be included.

- Relevant type of study Primary field studies.

- Language Full text written in English, Danish, Dutch, French, German, Norwegian, Spanish or Swedish.

\section{Systematic map output}

The final report will describe the review process and the evidence base, identifying possible knowledge gaps (i.e. subtopics requiring further primary research) and knowledge gluts (i.e. subtopics with enough evidence and interest to warrant a systematic review). The report will be accompanied by a database with the following kinds of metadata on each study that is included in the systematic map:

Full citation.

Language of article.

Country where the study was conducted.

Road type.

Adjacent land use.

Type of intervention.

Type of outcome.

Species or species group(s) studied.

Using the findings of the systematic map, we also intend to identify subtopics that may be suitable for full systematic review.

\section{Authors' contributions}

All authors participated in the drafting and revision of the manuscript. All authors read and approved the final manuscript

\section{Author details}

${ }^{1}$ Mistra Council for Evidence-Based Environmental Management, Stockholm Environment Institute, Box 24218, SE-104 51 Stockholm, Sweden. ${ }^{2}$ Centre for Ecology and Hydrology, Maclean Building, Benson Lane, Crowmarsh Gifford, Oxfordshire, Wallingford OX10 8BB, UK. ${ }^{3}$ Department of Physical Geography, Stockholm University, SE-106 91 Stockholm, Sweden. ${ }^{4}$ Department of Biology, Biodiversity, Ecology Building, Lund University, SE-223 62 Lund, Sweden. ${ }^{5}$ Forest and Nature Lab, Ghent University, Geraardsbergsesteenweg, 267, 9090, Gontrode, Melle, Belgium.

\section{Acknowledgements}

The review will be financed by the Mistra Council for Evidence-Based Environmental Management (EviEM).The Background section of this protocol is partly based on an unpublished pilot review conducted by Bo Söderström, EviEM.

\section{Competing interests}

The authors declare that they have no competing interests.

Received: 28 November 2015 Accepted: 5 February 2016

Published online: 29 February 2016 


\section{References}

1. Coffin AW. From roadkill to road ecology: a review of the ecological effects of roads. J Transp Geogr. 2007;15(5):396-406.

2. Reed RA. Johnson Bernard J, Baker WL. Contribution of roads to forest fragmentation in the rocky mountains. Conserv Biol. 1996;10:1098-106.

3. Forman RTT. Road ecology: a solution for the giant embracing us. Landsc Ecol 1998;13:III-V.

4. Forman RTT, Alexander LE. Roads and their major ecological effects. Annu Rev Ecol Syst. 1998;29:207-31.

5. Le Viol I, Julliard R, Kerbiriou C, de Redon L, Carnino N, Machon N, et al. Plant and spider communities benefit differently from the presence of planted hedgerows in highway verges. Biol Conserv. 2008;141(6):1581-90.

6. Eversham BC, Telfer MG. Conservation value of roadside verges for stenopic heathland Carabidae: corridors or refugia? Biodivers Conserv. 1994;3(6):538-45

7. Öckinger $\mathrm{E}$, Smith HG. Do corridors promote dispersal in grassland butterflies and other insects? Landsc Ecol. 2008:23:27-40.

8. Tikka PM, Högmander H, Koski PS. Road and railway verges serve as dispersal corridors for grassland plants. Landsc Ecol. 2001;16(7):659-66.

9. Auffret AG. Can seed dispersal by human activity play a useful role for the conservation of European grasslands? Appl Veg Sci. 2011;14(3):291-303.

10. Ansong $M$, Pickering $C$. Are weeds hitchhiking a ride on your car? A systematic review of seed dispersal on cars. PLoS One. 2013;8(11):e80275.

11. Zwaenepoel A, Roovers P, Hermy M. Motor vehicles as vectors of plant species from road verges in a suburban environment. Basic Appl Ecol. 2006;7(1):83-93.

12. Benton TG, Vickery JA, Wilson JD. Farmland biodiversity: is habitat heterogeneity the key? Trends Ecol Evol. 2003;18:182-8.

13. Vandermeer J, Perfecto I. The agricultural matrix and a future paradigm conservation. Conserv Biol. 2007:21:274-7.

14. Lindborg R, Plue J, Andersson K, Cousins SAO. Function of small habitat elements for enhancing plant diversity in different agricultural landscapes. Biol Conserv. 2014;169:206-13.

15. Szwed W, Sykora KV. The vegetation of road verges in the coastal dunes of the Netherlands. Folia Geobot and Phytotaxon. 1996;31(4):433-51.

16. Spooner PG, Lunt ID, Briggs SV, Freudenberger D. Effects of soil disturbance from roadworks on roadside shrubs in a fragmented agricultural landscape. Biol Conserv. 2004;117(4):393-406.

17. Rotholz E, Mandelik Y. Roadside habitats: effects on diversity and composition of plant, arthropod, and small mammal communities. Biodivers Conserv. 2013:22(4):1017-31.

18. Ruiz-Capillas P, Mata C, Malo JE. Road verges are refuges for small mammal populations in extensively managed Mediterranean landscapes. Biol Conserv. 2013;158:223-9.
19. Carthew SM, Garrett LA, Ruykys L. Roadside vegetation can provide valuable habitat for small, terrestrial fauna in South Australia. Biodivers Conserv. 2013;22(3):737-54.

20. Ottosson M, Lennartsson T, Svensson R. Nya vägar till artrikedom. Uppsala: Centrum för Biologisk Mångfald; 2012.

21. Rydgren K, Jorn-Frode N, Ingvild A, Inger A, Einar H. Recreating semi-natural grasslands: a comparison of four methods. Ecol Eng. 2010;36(12):1672-9.

22. Eriksson $\mathrm{O}$, Cousins $\mathrm{SAO}, \mathrm{Bruun} \mathrm{H}-\mathrm{H}$. Land-use history and fragmentation of traditionally managed grasslands in Scandinavia. J Veg Sci. 2002;13:743-8.

23. Noordijk J, Delille K, Schaffers AP, Sýkora KV. Optimizing grassland management for flower-visiting insects in roadside verges. Biol Conserv. 2009;142:2097-103.

24. Persson AS, Smith HG. Seasonal persistence of bumblebee populations is affected by landscape context. Agric Ecosyst Environ. 2013;165:201-9.

25. Auestad I, Rydgren $\mathrm{K}$, Jongejans $\mathrm{E}$, de Kroon H. Pimpinella saxifraga is maintained in road verges by mosaic management. Biol Conserv. 2010;143(4):899-907.

26. Stenmark M. Infrastrukturens gräs-och buskmarker. Hur stora arealer gräs och buskmarker finns i anslutning till transportinfrastruktur och bidrar dessa till miljömålsarbetet? Jönköping: Jordbruksverket Rapport. 2012;36.

27. Lennartsson T, Gylje S. Infrastrukturens biotoper- en refug för biologisk mångfald. Uppsala: Centrum för Biologisk Mångfald; 2009.

28. Van Meerbeek K. Low-input high-diversity systems: potential for biomass and bioenergy production. Leuven: KU Leuven, Belgium; 2015.

29. Auestad I, Rydgren K, Austad I. Road verges: potential refuges for declining grassland species despite remnant vegetation dynamics. Annales Botanici Fennici. 2011:48(4):289-303.

30. Svensson B. Från vägkant till ängsvägkant- är det möjligt?. Uppsala: Centrum för Biologisk Mångfald; 2013.

31. Doerr VAJ, Doerr ED, Davies MJ. Does structural connectivity facilitate dispersal of native species in Australia's fragmented terrestrial landscapes? Collab Environ Evid Rev. 2010;08:007.

32. Doerr ED, Doerr VAJ, Davies MJ, McGinness HM. Does structural connectivity facilitate movement of native species in Australia's fragmented landscapes? Sys Rev Protoc. Environ Evid. 2014;3:9.

33. von der Lippe M, Bullock JM, Kowarik I, Knopp T, Wichmann M. Humanmediated dispersal of seeds by the airflow of vehicles. PLoS One. 2013;8(1):e52733.

34. Suárez-Esteban A, Fahrig L, Delibes M, Fedriani JM. Can anthropogenic linear gaps increase plant abundance and diversity? Landscape Ecol. 2016. doi:10.1007/s10980-015-0329-7.

\section{Submit your next manuscript to BioMed Central and we will help you at every step:}

- We accept pre-submission inquiries

- Our selector tool helps you to find the most relevant journal

- We provide round the clock customer support

- Convenient online submission

- Thorough peer review

- Inclusion in PubMed and all major indexing services

- Maximum visibility for your research

Submit your manuscript at www.biomedcentral.com/submit
() Biomed Central 